\title{
Possible gasoline-induced chronic liver injury due to occupational malpractice in a motor mechanic: a case report
}

\author{
Mahesh Lakmal Gunathilaka', Madunil Anuk Niriella², Nathasha Vihangi Luke', Chathura Lakmal Piyarathna', \\ Rohan Chaminda Siriwardena ${ }^{2}$, Arjuna Priyadarshin De Silva ${ }^{2}$ and Hithanadura Janaka de Silva ${ }^{2}$
}

\begin{abstract}
Background: Hydrocarbon-induced occupational liver injury is a well-known clinical entity among petroleum industry workers. There are many types of hydrocarbon exposure, with inhalation being the most common. Hydrocarbon-induced occupational liver injury is a rarely suspected and commonly missed etiological agent for liver injury. We report a case of a non-petroleum industry worker with chronic liver disease secondary to hydrocarbon-induced occupational liver injury caused by chronic low-grade hydrocarbon ingestion due to occupational malpractice.

Case presentation: A 23-year-old Sri Lankan man who was a motor mechanic presented to our hospital with decompensated cirrhosis. He had been chronically exposed to gasoline via inadvertent ingestion due to occupational malpractice. He used to remove gasoline from carburetors by sucking and failed to practice mouth washing thereafter. On evaluation, he had histologically proven established cirrhosis. A comprehensive history and workup ruled out other nonoccupational etiologies for cirrhosis. The patient's long-term occupational gasoline exposure and clinical course led us to a diagnosis of hydrocarbon-induced occupational liver injury leading to decompensated cirrhosis.
\end{abstract}

Conclusions: Hydrocarbon-induced occupational liver injury should be considered as a cause when evaluating a patient with liver injury with possible exposure in relevant occupations.

Keywords: Hydrocarbon, Gasoline, Occupational liver injury, Chronic liver injury, Cirrhosis, Case report

\section{Background}

Hydrocarbons are organic substances composed of carbon and hydrogen molecules. They are classified as aliphatic, in which carbon moieties are arranged in chains, or aromatic, in which the carbon atoms are arranged in a ring. Halogenated hydrocarbons make up a subgroup of aromatic hydrocarbons in which one hydrogen atom is replaced by a halogen molecule [1]. Gasoline, kerosene, lubricating oil, mineral spirits, and organic solvents are commonly encountered hydrocarbons in day-to-day practice. Gasoline is a refined product of petroleum consisting of a complex mixture of aliphatic and aromatic hydrocarbons, additives, and blending agents. Additives

\footnotetext{
* Correspondence: maduniln@yahoo.co.uk

${ }^{2}$ Department of Medicine, Faculty of Medicine, University of Kelaniya, PO Box 6Thalagolla Road, Ragama, GQ 11010, Sri Lanka

Full list of author information is available at the end of the article
}

and blending agents are added to the hydrocarbon mixture to improve the performance and stability of gasoline.

There are many work activities associated with hydrocarbon exposure. Hydrocarbons in various forms are used in industrial processes such as paint manufacturing, automobile manufacturing and maintenance, and metal processing. Exposure to these toxins can be intentional or accidental, and the routes of exposure may be inhalational, owing to their being highly volatile, or via direct contact and absorption through the skin. A wide range of health hazards related to short-term and long-term exposure to hydrocarbons have been identified. Pulmonary complications, especially aspiration, are the most frequently reported adverse effect of hydrocarbon exposure [2].

Toxic hepatitis is a well-recognized complication, especially following exposure to halogenated hydrocarbons [3]. The main pathogenic mechanisms responsible for liver 


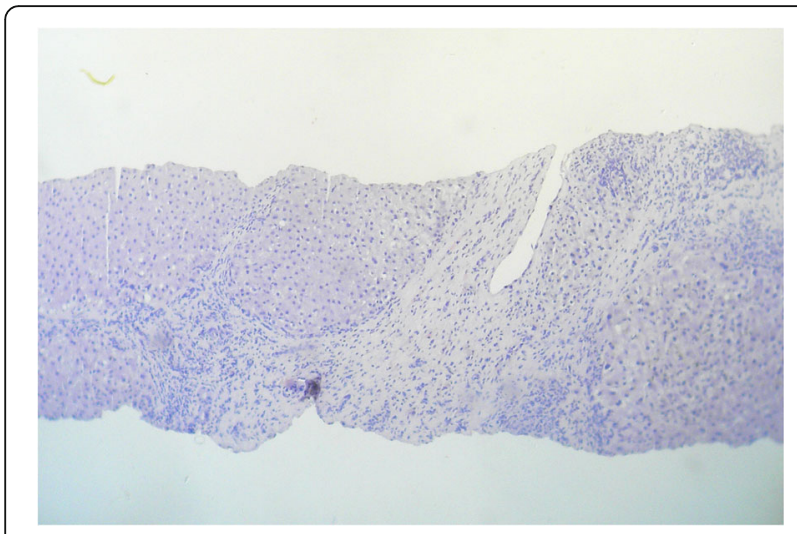

Fig. 1 Liver biopsy showing features of cirrhosis (hematoxylin and eosin stain, original magnification $\times 40$ )

damage caused by organic substances are inflammation, dysfunction of cytochrome P450, mitochondrial dysfunction, and oxidative stress [4]. Because the liver is the site of detoxification for most of these substances, it is exposed to the harmful effects of these toxins. Occupational toxic hepatitis can be divided into three types: hepatocellular, cholestatic, and mixed. Liver disease is likely to be more severe in the hepatocellular type, and elevated bilirubin in hepatocellular injury indicates serious liver disease [4]. Patients with cholestatic or mixed type are likely to develop chronic disease more frequently than those with hepatocellular type [4]. The common histopathologic pattern in toxic liver injury is centrilobular necrosis (zone III) necrosis. Liver biochemistry can be altered within 24 hours after ingestion of a toxic substance.

Although a number of organic substances are known to cause liver injury resulting from occupational exposure, hydrocarbon-related occupational liver injury (HC-LI) remains an underdiagnosed entity [5]. Three conditions must be fulfilled to diagnose toxic liver injury resulting from occupational exposure: (1) Liver damage should occur after occupational exposure to the toxic substance; (2) liver enzymes must increase to at least double the upper limit of normal; and (3) other causes of liver disease should be excluded [6].

Very little is known about the frequency and patterns of HC-LI. It is difficult to assess liver damage due to hydrocarbons in the workplace, owing to difficulties in quantifying exposure [7]. Therefore, individual case reports or case series on HC-LI are still valuable sources of knowledge. We report a case in a motor mechanic with HC-LI following chronic ingestion of gasoline resulting from occupational malpractice.

\section{Case presentation}

A 23-year-old Sri Lankan man, who had been working as a motor mechanic for approximately 5 years, presented to our hospital with a 2-month history of progressive, yellowish discoloration of the eyes; bilateral ankle swelling; and abdominal distention not associated with right hypochondrial pain, pruritus, or fever. His past medical history was unremarkable except for being prescribed furosemide by a general practitioner for edema. He denied intake of any other drugs, health supplements, or herbs. He had no history of smoking and only occasionally consumed alcohol in safe amounts (within Asian standard <14 U/week). His last alcohol consumption had been several months prior to the onset of symptoms. He had no family history of chronic liver disease. He had worked in a garage as a motor mechanic and used to remove gasoline from carburetors by sucking using his mouth when suction pumps were not available. He did not practice proper mouth washing and used to swallow petroleum compounds in substantial amounts during most of his working days. He had continued this malpractice for nearly 5 years until he developed symptoms.

His clinical examination revealed icterus and ankle edema with nontender hepatomegaly and moderate ascites. The results of the rest of his clinical examination were normal. His laboratory data were as follows: hemoglobin $12.2 \mathrm{~g} / \mathrm{dl}$, white blood cell count $8920 / \mathrm{mm}^{3}$, platelet count $204,000 / \mathrm{mm}^{3}$, erythrocyte sedimentation rate $16 \mathrm{~mm}$ at the end of the first hour, aspartate aminotransferase $190 \mathrm{U} / \mathrm{L}$, alanine aminotransferase $45 \mathrm{U} / \mathrm{L}$, alkaline phosphatase $465 \mathrm{U} / \mathrm{L}, \gamma$-glutamyl transpeptidase $72 \mathrm{U} / \mathrm{L}$, total bilirubin $26.4 \mathrm{mg} / \mathrm{dl}$ (direct bilirubin $12.8 \mathrm{mg} / \mathrm{dl}$ ), total protein $58.4 \mathrm{~g} / \mathrm{L}$ (albumin $23.2 \mathrm{~g} / \mathrm{L}$, globulin $35.2 \mathrm{~g} / \mathrm{L}$ ), prothrombin time 19.8 seconds (international normalized ratio 1.67), and serum creatinine $0.9 \mathrm{mg} / \mathrm{dl}$. His laboratory results were negative for anti-hepatitis A virus (HAV) immunoglobulin $M$ antibody, anti-HAV immunoglobulin G antibody, hepatitis B surface antigen, anti-hepatitis $C$ virus antibody, human immunodeficiency virus (HIV) antibody and antigen,

Table 1 Liver biochemistry of patient

\begin{tabular}{lllll}
\hline & On admission & On day 3 & On discharge & 6 weeks postdischarge \\
\hline ALT, U/L & 52 & 39 & 35 & 36 \\
AST, U/L & 205 & 160 & 80 & 55 \\
Total bilirubin, mg \% & 26.41 & 21.17 & 10.35 & 1.97 \\
ALP, U/L & 465 & 365 & 253 & 123 \\
\hline
\end{tabular}

Abbreviations: ALT Alanine aminotransferase, AST Aspartate aminotransferase, ALP Alkaline phosphatase 
antinuclear antibody, anti-smooth muscle antibody, and antimitochondrial antibodies. His levels of serum ferritin, serum copper, and serum ceruloplasmin were within normal ranges. The result of slit-lamp biomicroscopy was normal. Abdominal ultrasonography revealed hepatomegaly with a coarse hepatic echotexture suggestive of cirrhosis, portal hypertension, and moderate ascites without focal liver lesions. Esophagogastroduodenoscopy revealed small esophageal varices with portal hypertensive gastropathy. His liver biopsy revealed evidence of cirrhosis with regenerating hepatocytes, but with no clue to the underlying etiology of his liver disease (Fig. 1).

The patient was managed conservatively with symptomatic treatment. His regular medications included ursodeoxycholic acid, spironolactone, furosemide, lactulose, and carvedilol. His symptoms and laboratory parameters gradually improved during his hospital stay and stabilized over several weeks (Table 1). He was able continue his regular occupation with cautious handling of petroleum compounds. Given his advanced Child-Turcotte-Pugh (CTP) class C (CTP score 10/15) and high Model for End-Stage Liver Disease score (25), he is currently being worked up for a live-donor liver transplant.

\section{Discussion}

Our patient, a 23-year-old, previously healthy motor mechanic, presented to our hospital with decompensated cirrhosis. His history revealed chronic occupational exposure to gasoline via the oral route due to a malpractice in cleaning vehicle carburetors. A comprehensive workup ruled out other etiologies for cirrhosis. His liver biopsy confirmed established cirrhosis. His long-term occupational gasoline exposure and clinical course led us to a diagnosis of possible HC-LI leading to decompensated cirrhosis. Although not conclusively proven in this case, in the absence of other etiology and owing to our patient's chronic exposure to a well-known hepatotoxic agent with a compatible time course, we were led to the possibility of a clinical diagnosis of gasoline-induced chronic liver injury.

Numerous studies have suggested exposure to hydrocarbons, especially halogenated hydrocarbons, as a cause of hepatotoxicity $[8,9]$. Our patient fulfilled all diagnostic criteria for HC-LI [6]. The unique route of exposure through chronic low-grade ingestion and the patient's occupation indirectly related to exposure to petroleum products differentiated the present case from previously reported cases of HC-LI. HC-LI is rarely diagnosed, because it is not commonly suspected [5]. Therefore, taking a detailed history and maintaining a high index of clinical suspicion are needed for the diagnosis of HC-LI. This case highlights the consequences of occupational malpractice-related HC-LI, which can easily be prevented by health education among potentially exposed workers in high-risk work environments.

\section{Conclusions}

Chronic exposure to gasoline leading to HC-LI should be considered as an etiological factor for the development of cirrhosis in workers in occupations with possible exposure. Taking a detailed occupational history is necessary to establish HC-LI because this entity is underestimated and commonly missed in clinical practice. Because many young people in the economically productive age group are engaged in high-risk occupational activities, we suggest increasing awareness regarding mishandling of petroleumbased products to prevent the development of HC-LI and to reduce the burden on health care systems.

\section{Abbreviations}

ALT: Alanine aminotransferase; AST: Aspartate aminotransferase; ALP: Alkaline phosphatase; CTP: Child-Turcotte-Pugh; HAV: Hepatitis A virus; HC-LI: Hydrocarbon-related occupational liver injury

\section{Acknowledgements}

The authors thank Prof Janaki Hewavisenthi, Department of Pathology, Faculty of Medicine, University of Kelaniya, Ragama, Sri Lanka, for providing the photograph of the liver histology of this patient for publication.

\section{Funding}

None.

\section{Availability of data and materials}

Data supporting this case report can be obtained only through corresponding author on special request.

\section{Authors' contributions}

MLG, NVL, CLP, MAN, and RCS were involved in the clinical management of the patient. MLG drafted the initial manuscript. MAN, APDS, and HJdS completed a review of the literature and revised the manuscript critically for important intellectual content. All authors agree to be accountable for all aspects of the work. All authors read and approved the final manuscript.

\section{Competing interests}

The authors declare that they have no competing interests.

\section{Consent for publication}

Written informed consent was obtained from the patient for publication of this case report and any accompanying image. A copy of the written consent is available for review by the Editor-in-Chief of this journal.

Ethics approval and consent to participate

Not applicable.

\section{Publisher's Note}

Springer Nature remains neutral with regard to jurisdictional claims in published maps and institutional affiliations.

\section{Author details}

${ }^{1}$ University Medical Unit, Colombo North Teaching Hospital, Ragama, Sri Lanka. ${ }^{2}$ Department of Medicine, Faculty of Medicine, University of Kelaniya, PO Box 6Thalagolla Road, Ragama, GQ 11010, Sri Lanka.

Received: 7 April 2017 Accepted: 8 June 2017

Published online: 03 July 2017

\section{References}

1. Mowry JB, Spyker DA, Cantilena Jr LR, McMillan N, Ford M. 2013 Annual Report of the American Association of Poison Control Centers' National Poison Data System (NPDS): 31st annual report. Clin Toxicol (Phila). 2014; 52(10):1032-283.

2. Seymour FK, Henry JA. Assessment and management of acute poisoning by petroleum products. Hum Exp Toxicol. 2001;20(11):551-62. 
3. Palmer RB, Phillips SD. Chlorinated hydrocarbons. In: Shannon MW, Borron SW, Burns MJ, editors. Haddad and Winchester's clinical management of poisoning and drug overdose. 4th ed. Philadelphia: Saunders Elsevier; 2007. p. 1347-61.

4. Malaguarnera G, Cataudella E, Giordano M, Nunnari G, Chisari G,

Malaguarnera M. Toxic hepatitis in occupational exposure to solvents. World J Gastroenterol. 2012;18(22):2756-66. doi:10.3748/wjg.v18.i22.2756.

5. Døssing M. Occupational toxic liver damage. J Hepatol. 1986;3(1):131-5.

6. Maria V, Victorino R. Development and validation of a clinical scale for the diagnosis of drug-induced hepatitis. Hepatology. 1997;26(3):664-9.

7. Brautbar N, Williams 2nd J. Industrial solvents and liver toxicity: risk assessment, risk factors and mechanisms. Int J Hyg Environ Health. 2002;205(6):479-91.

8. Franco G, Fonte R, Candura F. Hepatotoxicity of organic solvents. Br J Ind Med. 1986:43(2):139.

9. Franco G, Fonte R, Tempini G, Candura F. Serum bile acid concentrations as a liver function test in workers occupationally exposed to organic solvents. Int Arch Occup Environ Health. 1986;58(2):157-64.

Submit your next manuscript to BioMed Central and we will help you at every step:

- We accept pre-submission inquiries

- Our selector tool helps you to find the most relevant journal

- We provide round the clock customer support

- Convenient online submission

- Thorough peer review

- Inclusion in PubMed and all major indexing services

- Maximum visibility for your research

Submit your manuscript at www.biomedcentral.com/submit
Biomed Central 